\title{
Factor Analysis Affecting LOS in Yellow Triage Emergency Room at Bangil Hospital during the COVID-19 Pandemic
}

\author{
Firdaus Kristyawan ${ }^{1}$, Nurdiana ${ }^{2}$, Rinik Eko Kapti ${ }^{3}$ \\ ${ }^{1}$ Master Program of Nursing, Faculty of Medicine, University of Brawijaya, Malang, \\ Indonesia \\ ${ }^{2,3}$ Faculty of Medicine, University of Brawijaya, Malang, Indonesia \\ Email: firdaus93@student.ub.ac.id
}

\begin{abstract}
Length of Stay (LOS) is a major problem that occurs in hospital emergency rooms because it needs quick and precise handling of its services, especially during the COVID-19 pandemic. LOS prolongation can lead to worsening of the patient's condition, increased costs, and mortality. Many factors cause LOS, but it is known that there several factors that affect LOS in the ER, including the duration of laboratory examinations, duration of radiological examinations, duration of specialist doctor consultation, and duration of the process of transferring patients in the ER. The aim of the study was to determine the most dominant factor and the big influence on LOS in the Bangil ER during the COVID-19. This research was a quantitative observational analytic with a cross-sectional approach that used LOS observation and a digital clock for recording. Participants were 109 patients who were admitted to the yellow triage IGD and received COVID-19 protocol. The results showed that there was a significant relationship between the duration of specialist doctor consultation and patient transfer process to LOS with a probability of 0.000 and then the duration of the patient transfer process is the most dominant factor compared the others with a beta value 0.625 . The duration of the patient transfer is the most dominant factor in LOS. Further research could be focused on the specific disposition of inpatient or hospital discharge. Then regarding the pandemic, it is possible to examine variables related to COVID-19.
\end{abstract}

Keywords: Length of Stay, Emergency Room (ER), COVID-19.

\section{A. INTRODUCTION}

LOS IGD is the length of time for a patient to stays in the ER, starting from a patient enters the ER to leaving the ER. According to Mc Charthy in 2013, throughout the world, the need for patients to get services in the emergency room continued to increase by 65\% from 2001 to 2011 (Ahmed et al., 2020). LOS is used as an indicator for assessing the quality and efficiency of emergency services in the ER (Wilson, 2016). It is known that the average LOS time in the IGDs in the Netherlands, England, and Canada is 4 hours (Higginson, 2012; Vegting et al., 2015; Vermeulen et al., 2016). Meanwhile, the average LOS time in Indonesia is varied, but based on the 2011 Health Office standard it is $<6-8$ hours.

LOS prolongation in the ER harms patients, including worsening the patient's condition, increasing costs, increasing the incidence of medical errors, and death (Singer et al., 2011). In one study in Australia, prolongation of LOS IGD for more than 8 hours resulted in a mortality rate of around 1500 deaths per year (Morris et 
al., 2012). To reduce and avoid the impact of LOS lengthening, it is necessary to identify the causes of LOS in the ER.

The causes of LOS lengthening in the ER are divided into 3 aspects, namely input, throughput, and output (Bellow \& Gillespie, 2014). The throughput aspect is the most influential area for LOS in the ER, starting when the patient enters until leaving the ER (Kusumawati et al., 2019; Purwacaraka et al., 2019). The variables in the throughput area include the duration of laboratory examinations, duration of radiological examinations, duration of specialist doctor consultation, and duration of the patient transfer process.

Laboratory examinations are related to doctor requests, nurse skills, communication processes, and analysis from the laboratory (Kawano et al., 2014). A radiological examination is carried out by the radiographer at the request of the doctor according to the indication of the disease and is assisted by a nurse in the process. Radiological examinations in the ER include X-ray, CT Scan, and USG (Vegting et al., 2015). The Doctor Consultation Process has an influence on LOS in the IGD. It is proven in research in the emergency room of Jogja hospital, patients with a consul to a specialist are 160 minutes longer in the emergency room than patients without consulting a specialist (Kusumawati et al., 2019). In a process of transferring the patient is divided into 2 parts, namely MRS or hospitalized patients and KRS (out of hospital). The process of transferring patients has a strong relationship with LOS in the ER (Driesen et al., 2018; Purwacaraka et al., 2019; Vegting et al., 2015).

It is known that the Covid-19 factor plays a role in emergency services in hospitals. According to Palinkas et al (2020), there are 4 impacts of Covid-19 on emergency services, namely Covid-19 Epidemiology, the outside regulatory sector, internal regulation (organization), and individual patients (Palinkas et al., 2020).

Bangil Hospital is a regional hospital in Bangil, Pasuruan with type B. The number of patients has increased by 20\% from 2015 to 2016. And the average number of visits to the ER in 2019 was 2000 visits with the majority of patients in the yellow category / Priority 2 (2 / 3 of the number of visits in the ER). The research was carried out in June 2020 at the time of the COVID-19 pandemic around the world and Indonesia (the Pasuruan regional government implemented large-scale social restrictions (PSBB). The implementation of the COVID-19 Protocol implements additional tasks in health services, namely the screening process, self-protection, and maintaining social distancing. (Protokol Pencegahan Penularan Covid-19 Di Tempat Kerja, 2020). It is estimated that this affects the LOS in the ER. This study aimed to analyze the most dominant factors on LOS and to determine the strength of its influence. It is hoped that by knowing the causative factors, a solution can be found to overcome the lengthening of the duration of LOS in the ER, especially during a pandemic. 


\section{B. METHOD}

This research was conducted at the Bangil Pasuruan Regional General Hospital for 20 days in June 2020. This research is a quantitative study using an observational analytic design. Meanwhile, the research design used was crosssectional, where the independent variables (duration of laboratory examinations, duration of radiological examinations, duration of specialist doctor consultation, and duration of patient transfer process) affected the dependent variable (duration of LOS) occurred in an object of research is measured or collected at the same time.

The sample in this study were emergency room patients at Bangil Pasuruan Hospital. The sample size in this study was 109 people. Sampling used is a consecutive sampling technique by taking at a certain time according to inclusion and exclusion criteria. These criteria include the yellow triage category, not experiencing re-triage, and at least get one laboratory and radiological examination.

The independent variables in this study were duration of laboratory tests, duration of radiological examinations, and duration of specialist doctor consultation, and the duration of the patient transfer process. The dependent variable in this study was the duration of the patient's LOS while in the ER.

The research instrument used in this study was the observation sheet. The LOS Observation Sheet contains boxes and tables that describe the actions and duration of time experienced by the patient while the patient is in the ER. Digital clock measuring instruments are also used to record the time of events experienced by patients. Characteristics of respondents were patients with yellow triage, and according to the inclusion and exclusion criteria.

The observation format uses an observation sheet that researchers developed from research (Martin et al., 2011) dan (Kusumawati et al., 2019). The LOS observation sheet format in the ER consists of respondent data, laboratory examination time, radiology examination time, specialist doctor consultation time, and the time the patient moved.

The instruments in this study have passed the validity and reliability tests. The observation sheet research tool was consulted by two experts, namely from Ns. Purwoko Sugeng H, M Kep as main referral hospital senior nurses, and dr. Aurick Yudha, Sp. Em as an emergency specialist at the main referral hospital.

Data analysis in this study used Spearmen Rank and Regression using the SPSS 2.0 program. Data analysisSpearmen Rank aims to determine whether or not there is a significant relationship between the independent variables on LOS. Regression data analysis aims to see the strength of the relationship between variables and determine the most dominant factor for LOS in the ER.

In carrying out this research, the researcher has obtained permission from the Health Research Ethics Commission of the Faculty of Medicine, the University of Brawijaya based on a letter of Ethical Clearance ("Ethical Clearance") No. 77 / EC / KEPK - S2 / 03 / 2020. Ethical considerations were applied in conducting to ensure the protection of research subjects. 


\section{RESULT AND DISCUSSION}

The following describes the initial data of patient respondents before calculating the duration of the patient, including the time of arrival of the patient, gender, and age category.

Table 1 Characteristics of Respondents

\begin{tabular}{|c|c|c|}
\hline Time of arrival & Frequency & Percentage \\
\hline Morning & 34 & 31.2 \\
\hline Noon & 49 & 45.0 \\
\hline Night & 26 & 23.9 \\
\hline Gender & Frequency & Percentage \\
\hline Male & 69 & 63.3 \\
\hline Women & 40 & 36.7 \\
\hline Age & Frequency & Percentage \\
\hline$<14$ years & 10 & 9.2 \\
\hline $15-65$ years & 85 & 78.0 \\
\hline$>65$ years & 14 & 12.8 \\
\hline
\end{tabular}

Based on the table above, it is known that there are 109 respondents to the Yellow Triage IGD at Bangil Pasuruan Hospital. Based on the hours of arrival, more patients came during the day shift (range 14.00 to 21.00) totaling 49respondents. The majority of patients were male with 69 respondents. The characteristics of respondents in the age category were divided into 3 categories based on Vegting's previous research in 2015, namely less than 14 years, 15-65 years, and more than 65 years. The results are dominated by age (15 - 65 years) with several 85 respondents.

The data collection is obtained from the time difference between the start of the measurement hour to the completion of the measurement. There are four variables for which duration is measured, namely radiological examinations, laboratory examinations, specialist doctor consultations, and the patient transfer process. The results of research related to these variables can be seen in the following table:

Table 2 Characteristics of the Duration of the Respondents

\begin{tabular}{lccc}
\hline \multicolumn{1}{c}{ Numeric Variables } & Min & Maks & Average \\
\hline Radiology Examination Duration & 2 & 723 & 103.2 \\
Duration of Laboratory Examination & 28 & 1174 & 141.7 \\
Specialist Doctor Consultation Duration & 1 & 768 & 136.6 \\
Transfer Process Duration & 10 & 1215 & 180.1 \\
LOS duration & 160 & 2237 & 608.0 \\
\hline
\end{tabular}

Based on the table, it is known that the duration of radiological examination took a mean time of 103.2 minutes (1.72 hours). In the laboratory examination duration a mean of 141.7 minutes. The average duration of consultation with a specialist is 136.6 minutes. The duration of the patient transfer process obtained a 
mean time value of 180.1 minutes. And the duration of LOS (Length of Stay) or the length of stay of the patient in the emergency room obtained a mean time of 608 minutes.

Regarding the relationship between the independent variables on LOS, it can be seen by the SPSS test. The SPSS test used is the Spearman test because it measures the correlative hypothesis (numeric-numeric) and has an abnormal distribution, namely the Kolmogorov Smirnov alpha value of less than 5 percent. The following are the results of the Spearman test for each variable.

Tabel 3 Spearman Test

\begin{tabular}{lcc}
\hline \multicolumn{1}{c}{ Variable } & $\begin{array}{c}\text { P-value (Probabilitas } \\
\text { significancy) }\end{array}$ & $\begin{array}{c}\text { Correlation } \\
\text { coefficient }\end{array}$ \\
\hline Radiology Examination Duration & 0.344 & 0.092 \\
\hline Duration of Laboratory Examination & 0.063 & 0.179 \\
\hline Duration of the specialist doctor consul & 0.000 & 0.543 \\
\hline The duration of the moving process & 0.000 & 0.566 \\
\hline
\end{tabular}

In the table above, the independent variables that have a significant relationship with LOS $(p<0.05)$ at the time of bivariate analysis (Spearman Test) are the duration of specialist doctor consultations with a correlation coefficient of 0.566 and the duration of the patient transfer process with a correlation coefficient of 0.543 . The variable duration of radiology examination and duration of laboratory examinations did not have a significant relationship ( $p>0.05)$ because it had a value of 0.344 and 0.63 , respectively.

After it was known that the variable duration of the specialist doctor consul and the transfer process had a significant relationship with LOS ( $p<0.05)$ in the ER, then a test was carried out to determine which variable had the most influence on LOS. The following describes the results of the dummy regression test to determine the most influential variables on LOS.

Tabel 4 Regresi Dumy Test

\begin{tabular}{lc}
\hline \multicolumn{1}{c}{ Model } & Standardized Coefficients Beta \\
\hline Duration of doctor consultation & 0.409 \\
\hline Duration of the patient transfer process & 0.625 \\
\hline
\end{tabular}

In the table above, it can be seen that the variable that most influences LOS in the ER is the duration of the patient transfer process with a beta coefficient score of 0.625, while the duration for a specialist doctor consul is 0.409. Beta values have a range of 0 to 1 , where the closer to 1 , the more significant the impact.

The results of the study of 109 respondents with yellow triage patients in the IGD Bangil Pasuruan Hospital showed that the duration of the patient transfer process was the most influential factor on LOS of patients in the ER with a score of 0.625 (close to the number: 1 ). 
In the research data, the results showed that laboratory tests did not have a significant relationship with LOS lengthening in the ER. This is different from the research of Getahun et al (2019) and Purwacaraka et al (2019) which explains that laboratory tests have a strong effect on LOS in the ER (Getahun et al., 2019; Purwacaraka et al., 2019). It is known that the duration of laboratory examinations depends on the number of laboratory requests determined by doctors and/or specialists. Lab tests carried out include DL (complete blood), GDA, (blood sugar while), FH (faal -hemostasis, namely PTT, APTT), liver function (SGOT and SGPT), rapid COVID-19, BUN, creatinine, serum electrolytes, and others.

There are several reasons that the duration of laboratory examinations does not affect LOS, namely the fast sampling process by nurses, the fast performance of the laboratory in providing lab results (soft copy or print out), and the number of laboratory sample requests that are not large due to the conditions of the COVID-19 Pandemic PSBB. 19 so that there is a reduction in the number of patients entering the ER (the average number of patients per month before the pandemic is reduced from 2000 patients/month to 400 patients/month).

From the data, it is known that radiological examination also has no relationship with LOS in the ER. This contrasts with the research of Kawano et al (2019) and Ismail (2018) that radiological examination has a strong effect on LOS (Ismail, 2018; Kawano et al., 2014).

The results of the analysis show that several reasons why radiological examinations do not affect LOS are the number of requests for radiological examinations that are not large (the number of patients entering the ER is not too many) and the speed of health services in conducting radiological examinations even though using the COVID-19 protocol (radiographers also use PPE or Personal Protection Equipment when doing the action).

In the variable duration, the specialist doctor consul is known to have a relationship with LOS but is not the main and most influential factor. This is supported by research belonging to Kusumawati (2019) which states that there is a variable effect of specialist doctor consultation on LOS with a mean duration of 435 minutes in the study (Kusumawati et al., 2019). In the research data, it is known that the average duration of specialist doctor consultation is 136.6 minutes (2.26 hours). The duration of the consultation is quite long because according to Fouk's (2016) study, the ideal average time for a consultation with a specialist in the ER is 65 minutes (Fouk, 2016).

The duration of consultation with a specialist is influenced by several things, namely the severity of the patient's condition, speed response of specialist doctors in reply to consuls, and the number of specialists. According to Kusumawati's (2019) research that good communication between consultants and emergency room doctors/nurses have a major effect on the flow of emergency services (Kusumawati et al., 2019). The results show that the majority of respondents need a lot of time to consult a specialist at night. This adds to the length of the consultation process, especially if the patient comes to the ER at night. 
The complexity of the conditions of the patient also contributed to the long duration of the consultation. According to Kusumawati's research that complex patient conditions require longer preparation when transferred to the room than patients with uncomplicated conditions (Kusumawati et al., 2019). Patients with complex conditions need investigation, adequate observation, and appropriate therapy. So it is recommended that the nurse or emergency room doctor immediately consult a specialist as soon as he finds that the patient requires consultation. Another solution to shorten the duration of LOS is that the IGD makes a policy to set a time limit for answering consultation requests so that specialist doctors can be more responsible (Schoenenberger et al., 2016). Suppose an agreement is made to answer the patient's consultation that it should not be more than 15 minutes since the initial consultation was given to a specialist.

The duration of the patient transfer is the duration of time calculated from the patient's disposition determined by the doctor until the patient leaves the emergency room (MRS or KRS). In the research data, it is known that out of 109 patients only 21 patients had KRS and the majority were sent to the inpatient room / MRS as many as 88 patients. In MRS patients, there is a confirmation process from the emergency room to the intended room (by telephone), administrative processes, and availability of beds from the room. These include inpatient rooms (classes I, II, and III), intensive rooms (CVCU, ICU, and $\mathrm{HCU}$ ), and OK room (operating room). In KRS patients, there are several options and possibilities, namely the patient is discharged, discharged (recovered), returns home at his own request (PAPS), and the patient is referred to another health facility (higher level). In this study, it was found that there was a significant relationship between the duration of patient transfer and the duration of LOS in the ER. There are several reasons for the prolonged duration of the patient transfer process.

The causes of the process of transferring MRS patients include lengthening the availability of a bed in the room and lengthening the duration when the patient leaves the ER. In the case of insufficient bed availability, this is related to the unavailability of the room class as registered and the non-availability of supporting equipment in the intended room (for example, a respirator in patients who need airway breathing, or a syringe pump for patients who need special medication in the room). According to Purwacaraka in 2019 that the patient was in the emergency room for a long time because there was no available bed in the class of the room as registered (especially classes 1 and 2) (Purwacaraka, 2019). The next cause is the prolongation of the duration when the patient leaves the emergency room, this is related to the delivery process such as delivering several patients simultaneously at one time, and the use of patient support equipment needed when transporting patients (syringe pump, infusion pump or oxygen transport) (Ismail, 2018; Purwacaraka, 2019). Regarding the completeness of the status and the results of the supporting examinations at the Bangil Pasuruan IGD for transfer to the room, it did not become a significant problem in terms of LOS lengthening. 
In the process of transferring KRS patients, the causes of lengthening the duration of patient transfer include the complexity of the process of referring patients to another hospital, the difficulty of finding a referral hospital for COVID19, and the long waiting queue for referral patients. According to Damayanti's (2017) research that referrals are a factor that causes the emergency room to become fuller (Damayanti \& Sutono, 2017). Bangil Pasuruan Hospital already has a ventilator and HFNC device but there are more needs for use, so it is necessary to refer patients to other hospitals. In the process of referring a patient, confirmation is required from the referral hospital, completeness of supporting data, referring chronology (resume), reasons for referring, and approval of the responsible doctor.

The mean duration of the overall patient transfer process was 180.1 minutes (3 hours). This is not following the standard time of the moving process to the room in all cases, which is 100 minutes (Fouk, 2016), so to improve the transfer process, repair and handling are needed for the parts that cause the process of moving MRS and KRS For example, by providing education to patients who will have MRS temporarily occupying an empty inpatient room first, then if the bed according to the class already exists, the patient is transferred back to the bed (Purwacaraka, 2019). The next suggestion is not to send the patient to the room at the same time as other patients, the meaning is to immediately send the patient when the patient has been decided to move by the doctor, and to be confirmed by the room on the condition that there is no emergency (stable condition) in the ER (Fouk, 2016).

The research was carried out during the COVID-19 pandemic, namely MayJune 2020 when the government implemented the PSBB (large-scale social restrictions) and implemented the COVID-19 protocol in all health services. This protocol implements additional service duties, namely the screening process, selfprotection and social distancing. This is thought to increase the burden and duties of health workers in the ER so that it can affect LOS in the ER. However, it is known that the number of emergency patients at Bangil Hospital per month is only about 400 patients. It is different from the time before the pandemic in 2019 which reached 1800 patients per month (Bangil, 2020). This makes the workload of nurses and other health workers in the emergency department lighter in providing health services. This is similar to the study of Palinkas et al., 2020, that despite significant changes in procedures that include COVID-19 screening of all treated patients, distancing arrangements, the use of personal protective equipment, and changes in the behavior of patients and emergency personnel but the overall impact of the pandemic on the emergency department is minimal. This is because the number of patients visiting the emergency room (hospital) is less than expected. The health system's rapid response also plays an important role in services in the ER (Palinkas et al., 2020).

This study is a single study whose results may not be the same as studies in hospitals in other areas because of the different patient populations and coverage areas. However, this study can reveal the effect of the selected factor on a group of patients in the emergency room in Bangil, Pasuruan. 
Another limitation is that this study did not divide the sample into 2 groups of disposition, namely MRS and KRS patients. This adjusts to the initial proposal and the original aim of the study to assess the relationship between the duration of the patient transfer process in units of minutes without differentiating between patients according to the MRS and KRS transfer processes.

\section{CONCLUSION}

The duration of patient transfer was the most influencing factor on LOS in the IGD Bangil Pasuruan Hospital. Another factor that affects LOS is the duration of consultation with a specialist. The duration of radiological and laboratory examinations did not have a significant relationship with LOS. It is known that for the LOS in the IGD Bangil Pasuruan Hospital the mean yellow triage is 608 minutes (10.13 hours). It is quite a long time since to use the Vermeulen standard, 2016 ( $<6$ hours) so that further improvement is needed to improve emergency services at Bangil Pasuruan Hospital.

\section{REFERENCES}

1. Ahmed, A. A., Ibro, S. A., Melkamu, G., Seid, S. S., \& Tesfaye, T. (2020). Length of stay in the emergency department and its associated factors at jimma medical center, southwest ethiopia. Open Access Emergency Medicine, 12, 227-235. https://doi.org/10.2147/OAEM.S254239

2. Bangil, R. M. R. (2020). Studi Pendahuluan Pra Penelitian Firdaus Kristyawan.

3. Bellow, A. A., \& Gillespie, G. L. (2014). The Evolution of ED Crowding: JEN JEN. Journal of Emergency Nursing, 40(2), 153-160. https://doi.org/http://dx.doi.org/10.1016/j.jen.2013.01.013

4. Damayanti, P., \& Sutono, S. (2017). Faktor-Faktor Yang Beresiko Terjadinya Pasien Stagnan Di Instalasi Gawat Darurat Rumah Sakit. Jurnal Keperawatan Klinis Dan Komunitas, 1(2).

5. Driesen, B. E. J. M., Van Riet, B. H. G., Verkerk, L., Bonjer, H. J., Merten, H., \& Nanayakkara, P. W. B. (2018). Long length of stay at the emergency department is mostly caused by organisational factors outside the influence of the emergency department: A root cause analysis. PLoS ONE, 13(9), 1-16. https://doi.org/10.1371/journal.pone.0202751

6. Fouk, M. (2016). Analisis Faktor Penyebab Keterlambatan Tindakan Dengan Length Of Stay Patients Admission Di Instalasi Gawat Darurat Rumah Sakit Umum Daerah Prof. Dr. WZ Johannes Kupang. Universitas Brawijaya.

7. Getahun, H. meskel A., Keneni Gutema, N., Rodamo, K. M., \& Hirigo, A. T. (2019). Factors associated with the length of stay in emergency departments in $\begin{array}{llll}\text { Southern-Ethiopia. } & B M C & \text { Research } & \text { Notes, }\end{array}$ https://doi.org/http://dx.doi.org/10.1186/s13104-019-4271-7

8. Higginson, I. (2012). Emergency department crowding. Emergency Medicine Journal, 29(6), 437-443. https://doi.org/10.1136/emermed-2011-200532. 
9. Ismail, A. (2018). Analisis Faktor yang Mempengaruhi Length of Stay Pasien di Instalasi Gawat Darurat Menggunakan Pendekatan Time Frame Guide Emergency Model of Care. Universitas Airlangga.

10. Kawano, T., Nishiyama, K., \& Hayashi, H. (2014). Execution of diagnostic testing has a stronger effect on emergency department crowding than other common factors: A cross-sectional study. PLoS ONE, 9(10). https://doi.org/10.1371/journal.pone.0108447

11. Protokol Pencegahan Penularan Covid-19 Di Tempat Kerja, 4 (2020).

12. Kusumawati, H. I., Magarey, J., \& Rasmussen, P. (2019). Analysis of factors influencing length of stay in the Emergency Department in public hospital, Yogyakarta, Indonesia. Australasian Emergency Care.

13. Martin, M., Champion, R., Kinsman, L., \& Masman, K. (2011). Mapping patient flow in a regional Australian emergency department: a model driven approach. International Emergency Nursing, 19(2), 75-85.

14. Morris, Z. S., Boyle, A., Beniuk, K., \& Robinson, S. (2012). Emergency department crowding: towards an agenda for evidence-based intervention. Emergency Medicine Journal: EMJ, 29(6), 460. https://doi.org/http://dx.doi.org/10.1136/emj.2010.107078

15. Palinkas, L. A., Whiteside, L., Nehra, D., Engstrom, A., Taylor, M., Moloney, K., \& Zatzick, D. F. (2020). Rapid ethnographic assessment of the COVID-19 pandemic April 2020 "surge" and its impact on service delivery in an Acute Care Medical Emergency Department and Trauma Center. BMJ Open, 10(10), 1-14. https://doi.org/10.1136/bmjopen-2020-041772

16. Purwacaraka, M. (2019). Analisis Faktor Yang Berhubungan Dengan Length of Stay Pasien di IGD Prioritas 2 (P2) RSUD Dr. Iskak Tulungagung. Universitas brawijaya.

17. Purwacaraka, M., Ahsan, A., \& Nasution, T. H. (2019). Correlation of Admision Time, Discharge Time and Patients Discharge Type With Length of Stay in Yellow Zone of Emergency Department. The Malaysian Journal of Nursing, 11(01), 10-15. https://doi.org/10.31674/mjn.2019.v11i01.002

18. Schoenenberger, L. K., Bayer, S., Ansah, J. P., Matchar, D. B., Mohanavalli, R. L., Lam, S. S., \& Ong, M. E. (2016). Emergency department crowding in Singapore: Insights from a systems thinking approach. SAGE Open Med, 4, 2050312116671953. https://doi.org/10.1177/2050312116671953

19. Singer, A. J., Thode, H. C., Viccellio, P., \& Pines, J. M. (2011). The association between length of emergency department boarding and mortality. Academic Emergency Medicine, 18(12), 1324-1329. https://doi.org/10.1111/j.15532712.2011.01236.x

20. Vegting, I., Alam, N., Ghanes, K., Jouini, O., Mulder, F., Vreeburg, M., Biesheuvel, T., Van Bokhorst, J., Go, P., \& Kramer, M. H. H. (2015). What are we waiting for? Factors influencing completion times in an academic and peripheral emergency department. 
21. Vermeulen, M. J., Guttmann, A., Stukel, T. A., Kachra, A., Sivilotti, M. L. A., Rowe, B. H., Dreyer, J., Bell, R., \& Schull, M. (2016). Are reductions in emergency department length of stay associated with improvements in quality of care? A difference-in-differences analysis. BMJ Qual Saf, 25(7), 489-498.

22. Wilson, S. (2016). Identifying disparity in emergency department length of stay and admission likelihood. World Journal of Emergency Medicine, 7(2), 111. https://doi.org/10.5847/wjem.j.1920-8642.2016.02.005 